Review

\title{
Ground-Based Radar Interferometry: A Bibliographic Review
}

\author{
Massimiliano Pieraccini *(D) and Lapo Miccinesi 1 \\ Department of Information Engineering (DINFO), University of Florence, via Santa Marta 3, 50139 Firenze, Italy; \\ lapo.miccinesi@unifi.it \\ * Correspondence: massimiliano.pieraccini@unifi.it
}

Received: 9 April 2019; Accepted: 27 April 2019; Published: 30 April 2019

check for updates

\begin{abstract}
Ground-based/terrestrial radar interferometry (GBRI) is a scientific topic of increasing interest in recent years. This article is a bibliographic review, as much complete as possible, of the scientific papers/articles published in the last 20 years, since the pioneering works in the nineties. Some statistics are reported here about the number of publications in the years, popularity of applications, operative modalities, operative bands. The aim of this review is also to identify directions and perspectives. In the opinion of authors, this type of radar systems will move forward faster modulations, wider view angle, MIMO (Multiple Input Multiple Output) systems and radar with capability to detect the vector of displacement and not only a single component.
\end{abstract}

Keywords: radar; interferometry; ground-based synthetic aperture radar; terrestrial radar interferometer

\section{Introduction}

Radar interferometry started as space technology. In the nineties, the satellites ERS-1, JERS-1, RADARSAT-1, and ERS-2 [1,2], made use of the phase information of radar images for detecting ground changes. Spaceborne Synthetic Aperture Radar (SAR) systems, operating from an orbit at $800 \mathrm{~km}$ altitude, provide impressive interferograms due to the ground displacement after an earthquake [3,4]. These extraordinary spaceborne developments had an early follow-up in analogue ground-based radar systems. Pioneering works anticipated some ideas. In 1997 [5], Tarchi et al. detected by radar the structural change of a beam in a large anechoic chamber. In 1999 [6], the same bulk laboratory equipment was used to detect the changes of a dam. In 2000, Pieraccini et al. [7] measured the deformations of a pedestrian bridge during its static test with a portable radar. In 2003 [8], a landslide was monitored by an interferometric Ground-based Synthetic Aperture Radar (GBSAR) for the first time.

In February 2000, a specifically modified radar system with one transmitter and two receivers (the second at the end of a $60 \mathrm{~m}$ mast that extended from the payload) flew on board the Space Shuttle Endeavour during the 11 day STS-99 mission [9]. This equipment was able to generate a high-resolution digital topographic database. Inspired by this exciting idea, a GBSAR has been modified for acquiring data with different baselines to obtain the Digital Elevation Model (DEM) of its field of view [10].

Currently, ground-based/terrestrial radar interferometry (GBRI) is a popular remote sensing technique for monitoring landslides, mines, bridges, towers, dams, and other civil infrastructures.

The strength of GBRI is its complementarity with spaceborne SAR [11-13], while the latter is a powerful and effective remote sensing technique for surveying large areas (many $\mathrm{km}^{2}$ ) at long term (return time in the order of several weeks or months), GBRI is suitable for monitoring small areas (from a single building to a slope) at short term (sampling time up to a few of minutes) as sketched in Figure 1. 


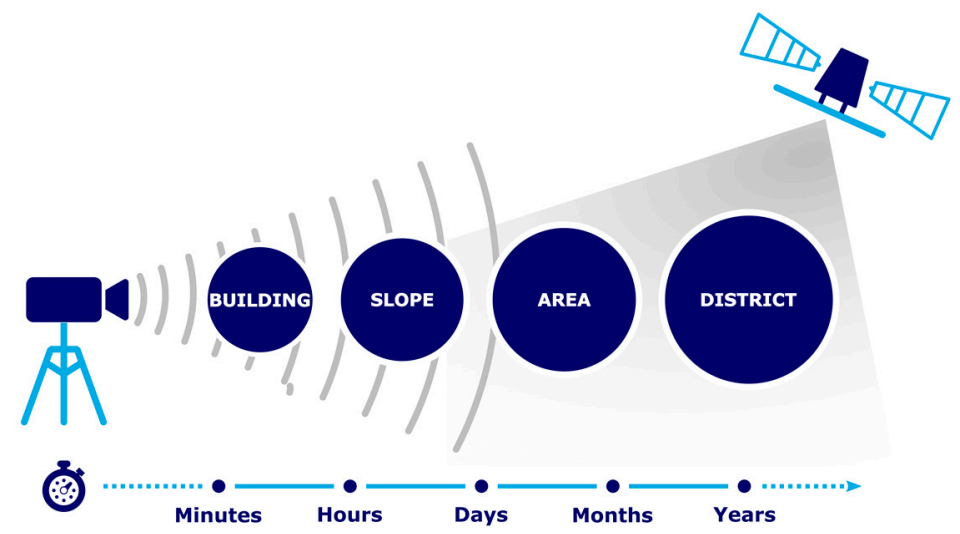

Figure 1. Complementarity of GBRI with spaceborne SAR.

After about twenty years of research and development in this field, the aim of this article is to review the vast literature and possibly identify further developments. This paper is focused on a bibliographic review; for more technical reviews on GBRI the reader can refer to [14-16].

This review is structured as follows. First, the authors recall briefly the working principle of GBRI. This kind of radar can operate without any Direction-of-Arrival (DOA) capability [17], or with a rotary system able to rotate the antenna [18]. More advanced DOA techniques include Synthetic Aperture Radar (SAR) [19] Multiple Input Multiple Output (MIMO) [20], and moving slot antennas [21]. These different designs are discussed, as well as the possible operative bands. Since GBRI is essentially a monitoring/testing technique, its applications are classified on the basis of items under test (or to be monitored) that can be landslides [8], bridges [7], buildings [22], mines [18], towers [23], glaciers [24], monuments [25], or volcanoes [26]. Finally, the authors discuss the most recent developments: FM modulation that reduces the sweep time [27], Arc-SAR modality that enlarges the view angle [28], MIMO that makes the radar dramatically faster [29], bistatic configurations that allows to detect the displacement vector [30], W-band that enlarge the bandwidth and reduce the size of the equipment [31], and radar systems with 3D imaging capabilities [32].

\section{Working Principle of GBRI}

With the term ground-based radar interferometer we define a ground-based piece of equipment that uses a microwave beam for remotely detecting small displacements of targets through phase measurement. Figure 2 shows the working principle of this kind of equipment. The reader can find a detailed description of the technique in the seminal papers [8,33].

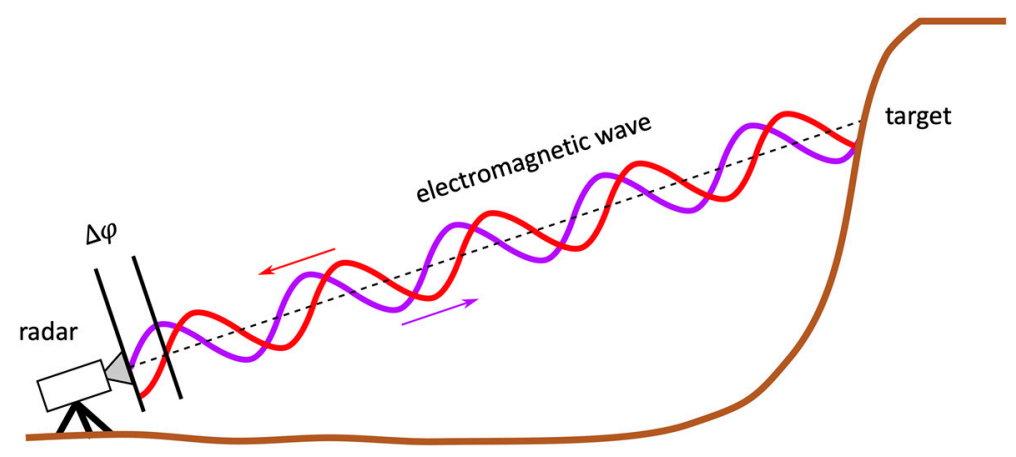

Figure 2. Working principle of ground based/terrestrial radar interferometry.

A transceiver installed at ground transmits an electromagnetic wave forward a target. The wave is backscattered and comes back to the transceiver that is able to detect the phase difference between 
the transmitted and the received wave. The phase difference $(\Delta \varphi)$ between two acquisitions is given by [16]

$$
\Delta \varphi=\Delta \varphi_{\text {disp }}+\Delta \varphi_{\text {atm }}+\Delta \varphi_{\text {noise }}
$$

where $\Delta \varphi_{\text {disp }}$ is given by the possible displacement of the target, $\Delta \varphi_{\text {atm }}$ is given by changes of the atmospheric conditions (humidity, temperature, pressure), and $\Delta \varphi_{\text {noise }}$ is a phase noise contribution that can never be completely eliminated in experimental measurements.

The atmospheric phase contribution (usually named "atmospheric phase-screen" [34]) can be neglected for short-range short-term applications (indicatively when the distance radar-target is less than 100-200 $\mathrm{m}$ and the time between the acquisitions is shorter than 1-2 h). In all other cases, the atmospheric phase screen has to be removed with suitable processing techniques. The proposed algorithms are many [35-37], but their working principle is always based on the identification of stable targets in the radar image and on the compensation with respect to them using a suitable (always approximated) atmospheric model. This phase-screen removal is a very critical point and limits the final accuracy in long term monitoring.

When the phase noise contribution is negligible and the atmospheric phase-screen is removed (or negligible), the possible displacement $(\Delta r)$ of the target between two acquisitions is detected as phase difference $(\Delta \varphi)$ through the following basic relationship [38]:

$$
\Delta r=\frac{\Delta \varphi}{4 \pi} \lambda
$$

with $\lambda$ wavelength of the transmitted signal.

In principle, it is possible to detect displacement even by using a non-modulated signal (i.e., transmitting a continuous wave at a single frequency, as for example in [39]), but without capability to discriminate the targets in range it is hard to separate the real displacement of the target of interest by the clutter. Therefore, the vast majority of these sensors transmits a modulated signal. In this case the range resolution $(\Delta R)$ is given by the bandwidth $(B)[40]$ :

$$
\Delta R=\frac{c}{2 B}
$$

with $c$ speed of light. A sensor with only range resolution works properly when the beam is narrow, and the target of interest extends mainly along a single dimension (like a tower or a bridge). For more complex targets (like slopes, buildings, villages) it is required a sensor with also cross-range resolution. This can be obtained in different ways. The simplest one is just with a mechanical system that rotates the antenna [41]. More advanced solutions are based on Synthetic Aperture Radar [42] or MIMO (Multiple Input Multiple Output) [43].

\section{GBRI in the Scientific Literature}

Since the pioneering works in the nineties, the scientific literature of GBRI has greatly grown involving several academic groups, private companies, and government agencies. In order to quantify the bibliographic impact of GBRI we have selected a set of relevant publications using SCOPUS, WEB OF SCIENCE, and Google Scholar with combinations of the following key words: ground-based synthetic aperture radar, interferometric radar, GBSAR, terrestrial radar interferometer, real aperture radar. All selected publications have been checked by the authors to exclude false-positives. The criteria we used for publication selection were: (1) relevance to the topic; (2) published before December 2018 (to avoid to update the record each day); (3) journal articles and conference papers (we have eliminated chapters of books, monographs, Ph.D. dissertations); (4) texts written in English; (5) accessible full-text via Institution (University of Florence). The result of this research was a set of 415 publications. The number of papers we have not been able to download has been less than ten, therefore we can estimate that the selected set of publications covers about $98 \%$ of relevant literature. Figure 3 shows 
the distribution of these publications starting in 1997 [5]. The average bibliographic production of the last four year is 42 publications per year.

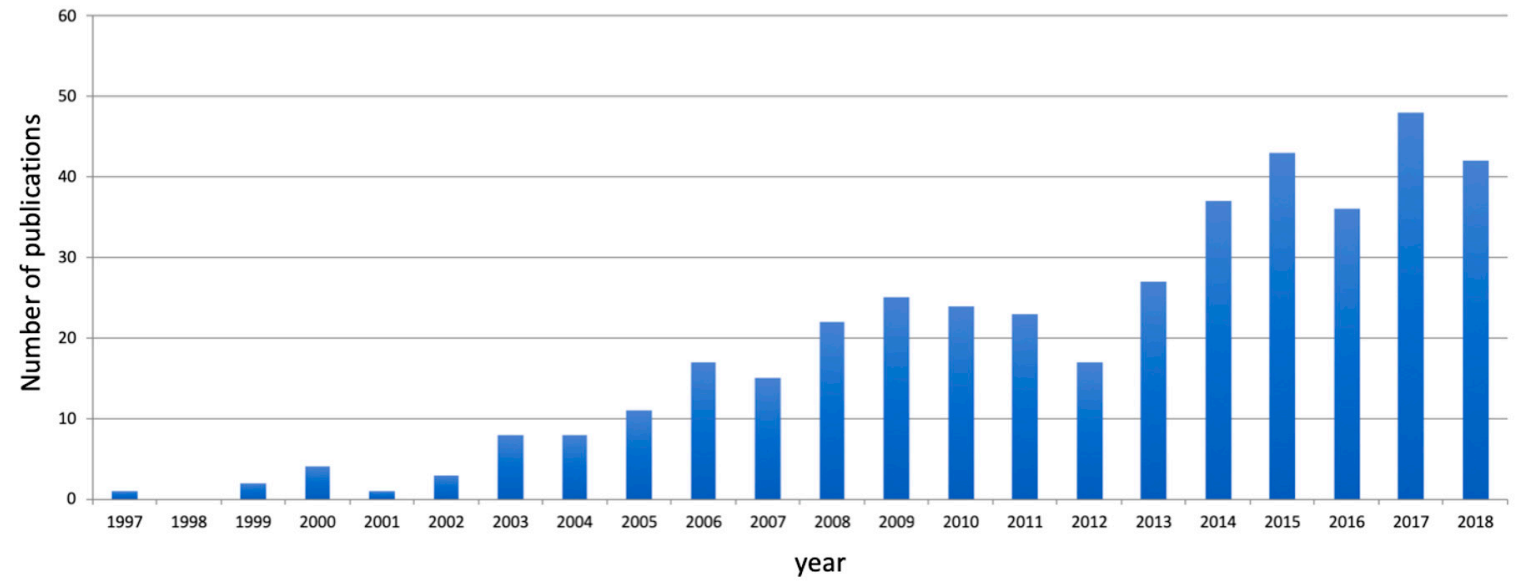

Figure 3. Papers published until December 2018 on GBRI.

Radars can detect a range by measuring the time-of-flight between the transmitted and received electromagnetic wave. The direction of arrival (DOA) cannot be detected (we refer to this kind or radar interferometer with the term "no-DOA"), $[17,23,39,44]$ or can be detected by the rotation of the radar head ("Rotary") without any synthetic aperture [18,45]. The most advanced radar systems are able to detect the direction of arrival through synthetic aperture (SAR: Synthetic Aperture Radar). The main advantage of SAR compared with equal aperture (physical or scanned) is that the angular resolution is twice good [19]. The simplest Ground-based Synthetic Aperture is based on the movement of a radar head along a linear mechanical guide ("linear SAR") [7,8]. Alternatively, it can be based on a circular movement (e.g., along an arc) $[28,46,47]$. We name this kind of radar "C-SAR". Finally, the synthetic aperture can be made with multiple transmitting antennas and multiple receiving antennas (MIMO: Multiple Input Multiple Output) [20,29]. A less common way to realize a synthetic aperture is to use the movement of a helicoidally slot [21]. Figure 4 shows pictures of some prototypes that exemplify these six operative modalities.

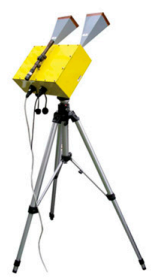

(a) no-DOA

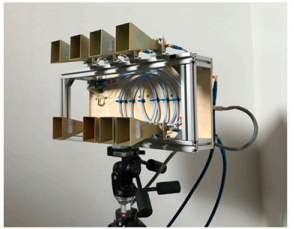

(d) MIMO

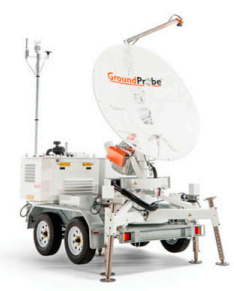

(b) rotary

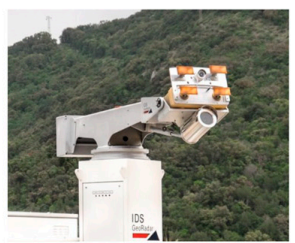

(e) $\operatorname{ArCSAR}$

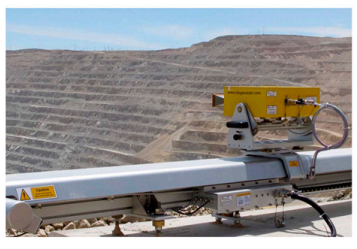

(c) linear SAR

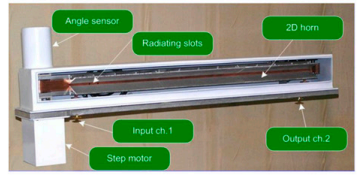

(f) moving slot

Figure 4. Examples of ground-based radar interferometers: (a) no-DOA (after [48]); (b) Rotary (after [49]); (c) linear SAR (after [48]); (d) MIMO (after [50]); (e) ArcSAR (after [48]); (f) moving slot (after [21]). 
As shown in the histogram in Figure 5, the majority of the papers refer to linear SAR (58\%) [7]. About $25 \%$ of the papers discuss developments or applications of radar interferometers without angular resolution ("real aperture"). About $8 \%$ of the publications refer to radar systems that achieve angular resolution just by rotating the antenna. These three operative modalities cover $91 \%$ of the publications.

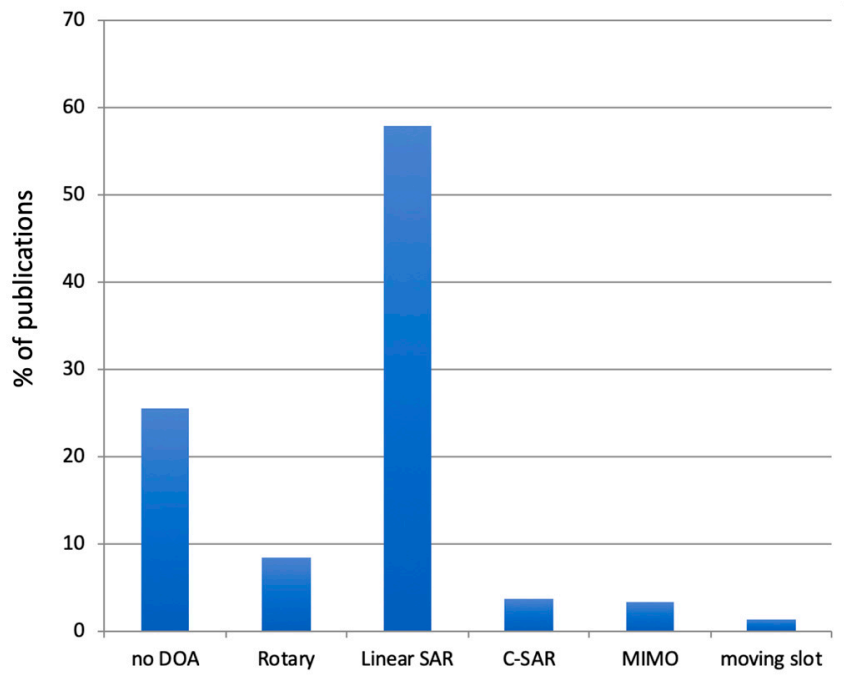

Figure 5. Papers published until December 2018 classified on the basis of the operative modality.

The operative band is a key parameter of a radar. Generally speaking, by increasing the operative frequency, the angular resolution improves and the displacement resolution increases. At the same time, the temporal coherence of the targets decreases. Therefore, a balance is necessary. Figure 6 shows the histogram of the publications divided on the basis of the chosen operative frequency of the radar. About $58 \%$ of publications are relative to equipment in $\mathrm{Ku}$-band $(12-18 \mathrm{GHz})$. Some radar systems operate in C-band (4-8 GHz), and X-band (8-12 GHz). The Ku-band is a good trade-off between size of the equipment and temporal coherence of the targets, even if the C-band is probably preferable for monitoring snow covers [51-53]. The components cost can be another issue that can make the difference in the selection of the band. Until today, components in Ka and W were more expensive, but with the large diffusion of automotive radar in W-band, their cost is rapidly decreasing [54].

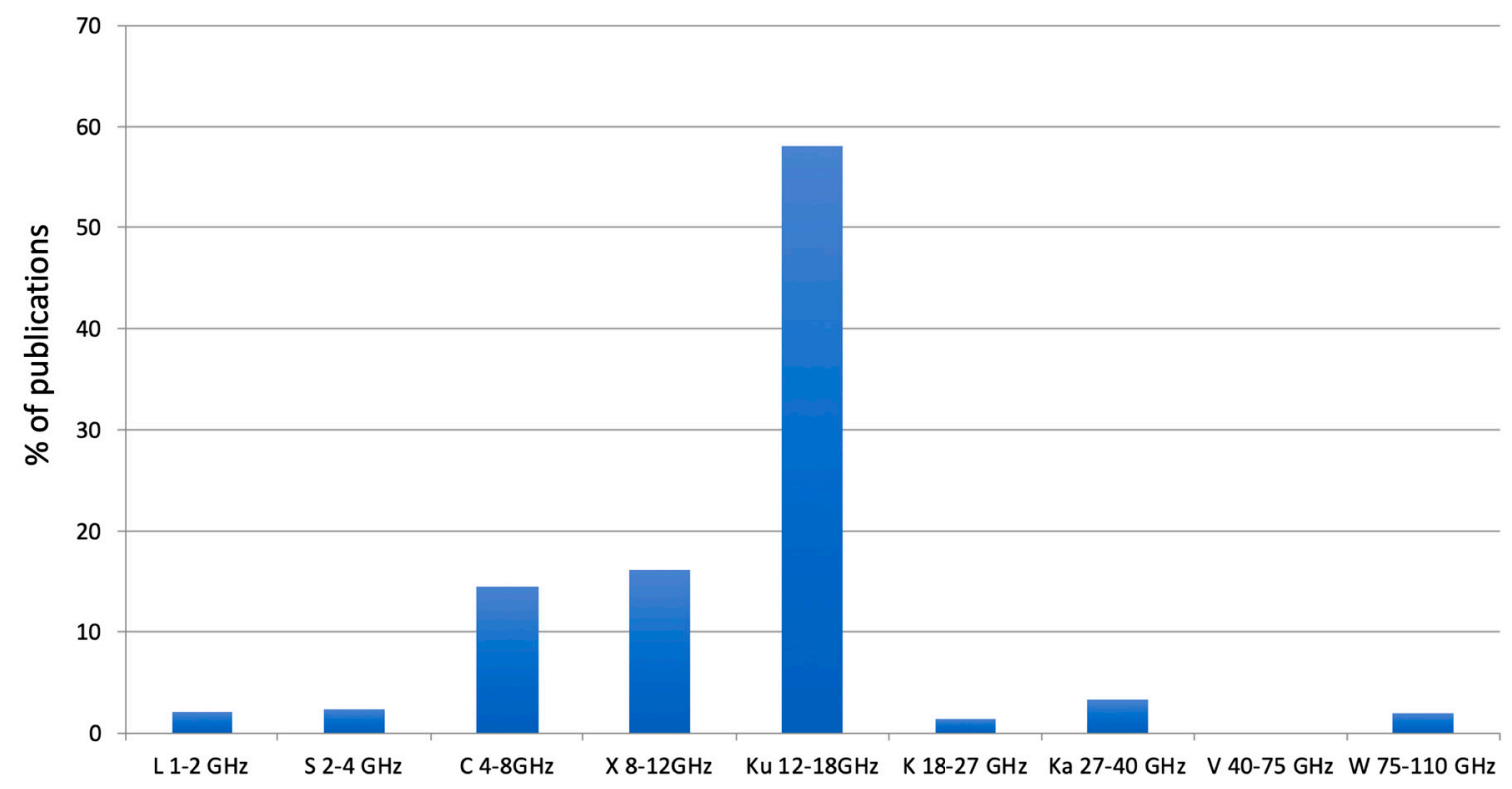

Figure 6. Papers published until December 2018 classified on the basis of the operative band. 
GBRI is an applicative topic. So, we have grouped the 415 publications based on the specific application. Obviously, a single publication can cover more than one application, and there are publications that do not refer to any specific application. The result of this classification in shown in Figure 7.

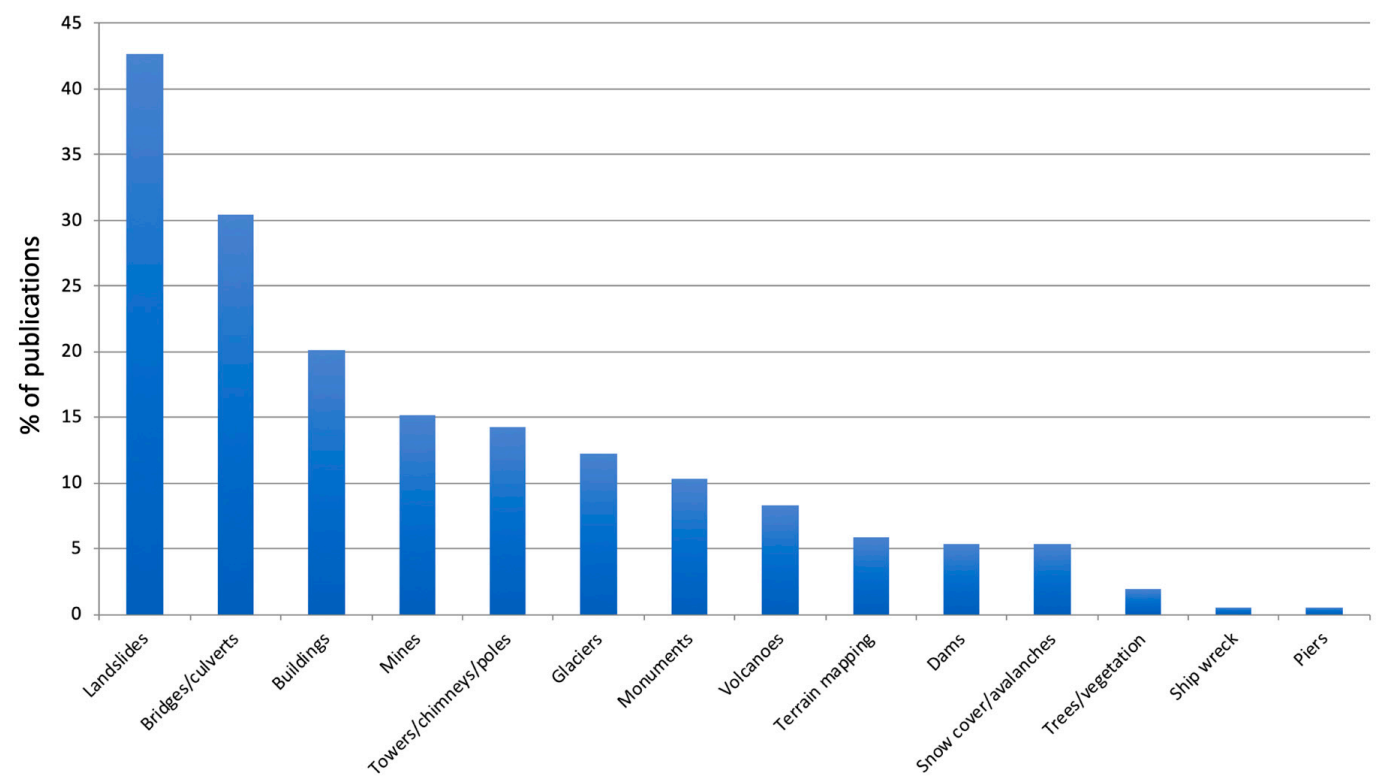

Figure 7. Papers published until December 2018 classified on the basis of their applications.

Landslide monitoring is doubtless the most popular application of GBRI (see Figure 8a). Sinkhole monitoring [55] has been included in this category. Over $40 \%$ of the publications are developments or case-studies about monitoring systems of landslides. The first in-field test dates back to 2003 [8]. Landslide monitoring is an application of great social and scientific impact and currently many slopes are routinely monitored by radar interferometers [56,57].

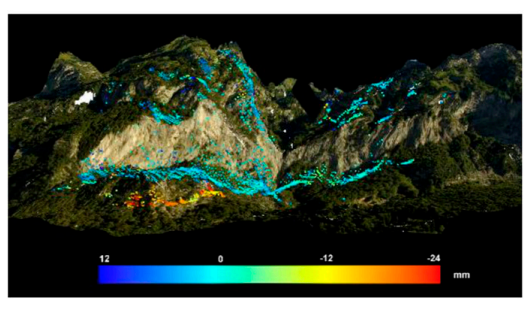

(a) landslides

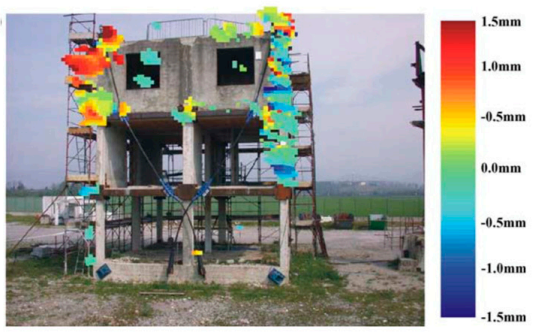

(c) buildings

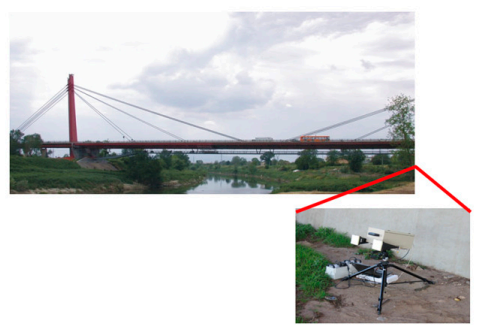

(b) bridges

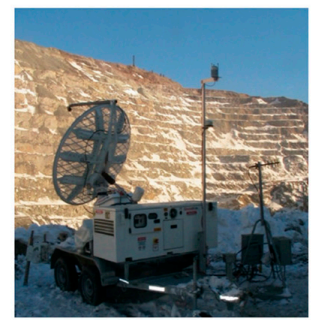

(d) mines

Figure 8. Examples of applications of GBRI: (a) landslide monitoring (after [58]), displacement map and picture projected on the digital elevation model of the slope; (b) monitoring of a viaduct in Florence, Italy; (c) displacement map projected on the picture of the monitored building (after [22]); (d) mines monitoring, radar deployed in Thompson Creek Mine, Idaho, USA (after [59]). 
In the application of GBSAR to landslide monitoring, the data acquired by ground-based radar installations are often integrated with geological and geomorphological field surveys, spaceborne SAR acquisitions (when available), orthophotos, and inventory maps. Figure 9 shows a typical data flow-chart [60].

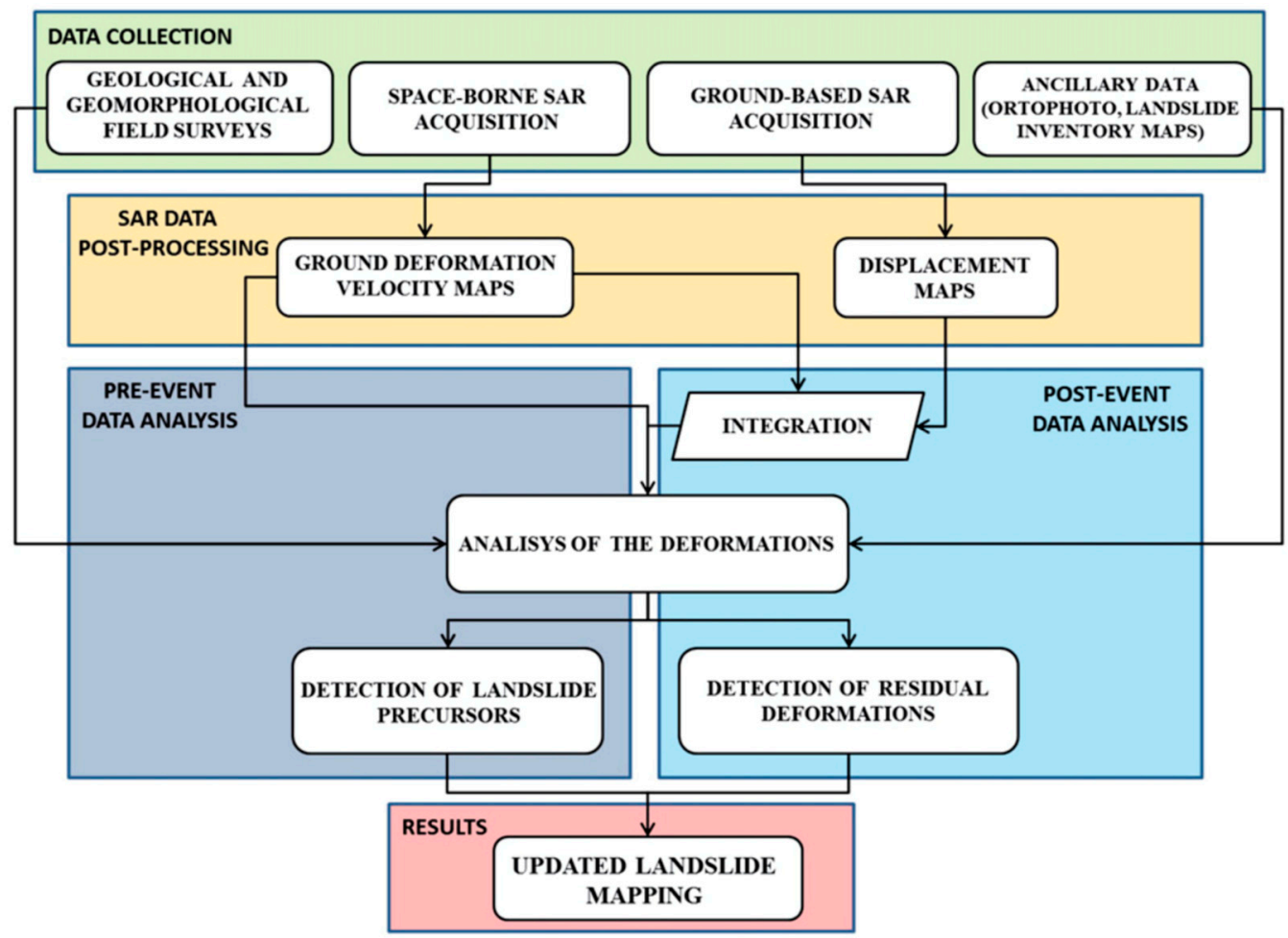

Figure 9. Data flow-chart that integrates geological and geomorphological field survey, space-born SAR acquisitions, orthophotos, and inventory map (after [60]).

Testing or monitoring of bridges is another key application (see Figure 8b). The radar is a fast, reliable and accurate equipment for remotely sensing the static or dynamic behavior of a bridge. Pieraccini et al. were the first (2000) that demonstrated [7] this possibility. Overall about 30\% of publications refer to bridge monitoring.

Building is the third class of applications in order of popularity (see Figure 8c). This class is less homogenous: we have considered radar systems that monitor construction works [61], villages built over landslide [62] or on terrain subject to subsidence [63]. Probably, this class of application is overestimated because many papers deal with the tests of equipment rather than their effective applications.

On the contrary, the class of the open pit mining is probably underestimated. At the knowledge of the authors, hundreds of radars are currently in operation as safety equipment in mining areas (see Figure $8 \mathrm{~d}$ )., but the number of publications on monitoring activity for worker safety in mining areas is rather modest (about 15\%). This is probably because mine safety is a rather confidential issue, and the owners hardly agree to publish their radar data. The first publication about it dates back to 2000 [18].

Monitoring of towers/chimneys/electric poles is another emerging application field of GBRI (see Figure 10a). Generally speaking, all nearly one-dimensional structures, like bridges and towers, are particularly suitable for being monitored/tested by radar, as it does not require cross-range resolution. Therefore, if radar operates in no-DOA modality the structure can be sampled at over 50-100 Hz [17,23], and its dynamic characteristics (natural frequencies, modal shape, transient response) can be detected. 


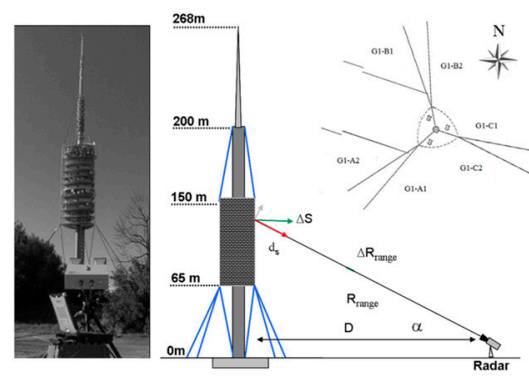

(a) towers

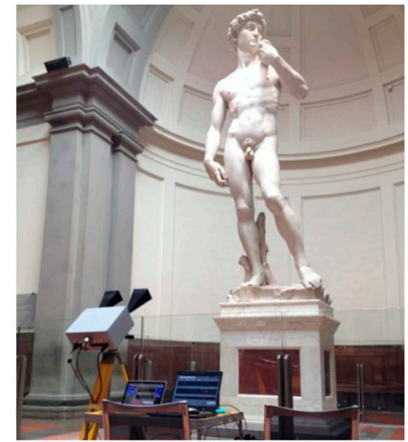

(c) monuments

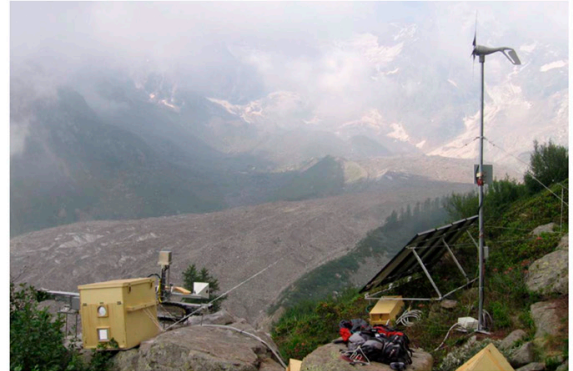

(b) glaciers

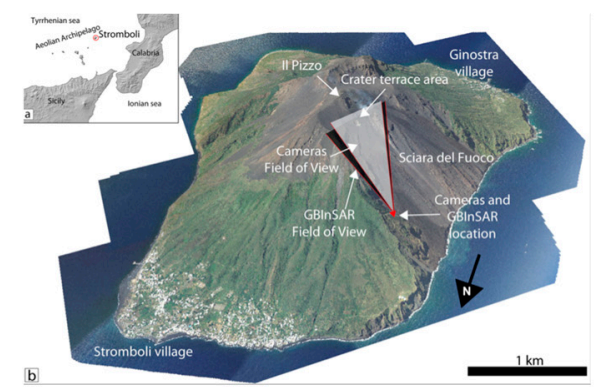

(d) volcanoes

Figure 10. Examples of GBRI applications: (a) towers (after [64]); (b) glaciers (after [65]); (c) monuments (after [25]); (d) volcanoes, permanent installation at the Stromboli volcano, Italy (after [66]).

Glaciers are fundamental "proxies" for standing the effects global warming on a local scale [67]. So, scientists have great interest in using GBRI for monitoring the change of glaciers (see Figure 10b). The first case study dates back to 2007 [24], but aftermath many other studies on different glaciers have been performed (see for example $[13,68,69])$. In our bibliographic survey about $13 \%$ of the papers refer to glacier monitoring.

Another field of application of great scientific and social interest is the monitoring of cultural heritage (see Figure 10c). Radar has been used for monitoring the lending Tower of Pisa, Italy [23]; the towers of San Gimignano, Italy [70], the Bell-tower of Giotto in Florence [71], the Michelangelo's David at Accademia Museum in Florence [25], the Baptistery of Florence, Italy [72], the ruins of Roman Forum of Rome, Italy [73], the retaining walls of the historical town of Volterra, Tuscany [74], and other sites $[75,76]$. Overall the publications the refer to Cultural Heritage represent about $10 \%$ of the total.

Volcanoes are both a fascinating phenomenon and an impending risk for people living around their flanks. Therefore, although the number of active volcanoes is rather limited, over $8 \%$ of the scientific papers refer to volcanoes. In particular, Stromboli volcano, Italy, (see Figure 10d) is one of the most studied volcanoes in the world [77-81] and it has been continuously monitored by terrestrial radar since 2008 [26]. Also, Soufrière Hills in the Montserrat island [82] and Hakone volcano in Japan [83] have been monitored by terrestrial radar.

Digital Elevation Model (DEM) production is another interesting GBRI application (see Figure 11a). Twelve papers ( $6 \%$ of total) have been published on this subject. The main finding is that this technique is effective even by a terrestrial radar, but its accuracy is sensibly worse than traditional equipment (photogrammetry or Terrestrial Laser Scanner) [10]. 


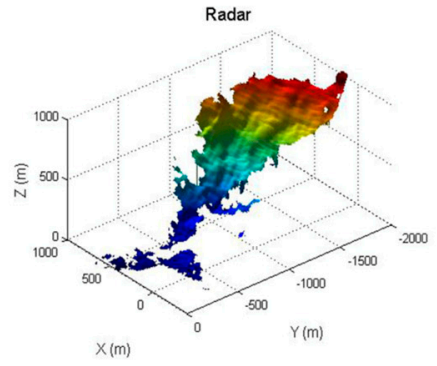

(a) Terrain mapping

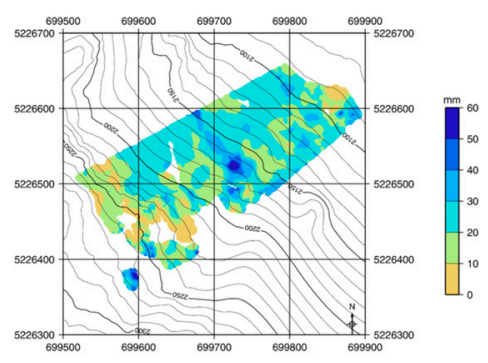

(c) snow cover

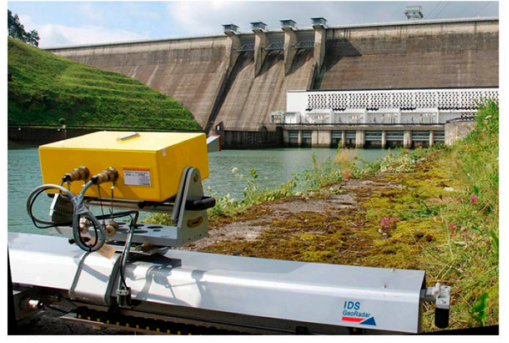

(b) dams

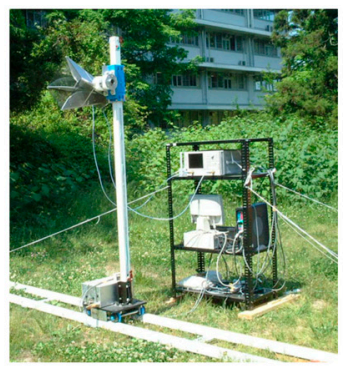

(d) trees

Figure 11. Examples of GBRI applications: (a) terrain mapping, digital elevation model of a slope obtained through GBSAR (after [84]) (b) dams monitoring (courtesy of IDS georadar [48]); (c) snow cover monitoring, map of snow water equivalent change obtained by GBSAR (after [85]); (d) trees monitoring by GBSAR (after [86]).

Dam-monitoring has been the first in-field application of GBRI: it dates back to 1999 [6] (see Figure 11b). The concrete surface of a dam is almost an ideal target for radar interferometry; it is coherent, homogenous enough but not specular. Nevertheless, the papers related to this application are only $5 \%$ of total, but dams have already sophisticated monitoring systems with different sensors [87], so there is no demand for novel sensors; and dam safety, as well as mines, is a rather confidential issue, and the owners hardly agree to publish their radar data.

Martinez-Vazquez in 2005 [51] proposed the GBRI for assessing snow cover change (see Figure 11c), as it has already been done by satellite [88]. The technique's results are effective with dry snow, while wet snow can be a problem [52]. Very interesting results have been obtained using the radar for mapping the avalanches on steep slopes [53].

Monitoring of vegetation or trees by GBSAR (see Figure 11d) [86] is again a marginal application ( $2 \%$ of the total).

Finally, it is worth noting two very peculiar applications. On January 2012, the Italian cruise ship Costa Concordia ran aground and overturned after striking an underwater rock close to the Isola del Giglio, Tuscany. The wreck came to rest on a rock ledge several months before its translation and decommissioning. In this period, an interferometric radar was installed over a rock of the island for monitoring possible displacements of the wreck [89]. The radar detection of the displacement of a pier pulled by a tugboat is the second noteworthy application [90].

These are the applications that we can find in the scientific literature, but they surely do not exhaust all the possibilities of GBRI. Just as an example of a possible interesting development, we can refer to some preliminary works on the use of radar for monitoring wind turbines [91,92]. The rotation of the blades gives a peculiar doppler signature (named "sinogram"); Li et al. [93] had the idea to apply the ISAR (Inverse Synthetic Aperture Radar) techniques for focusing the sinograms. In this way they obtained high-resolution radar images of the blades. A further step could be processing interferograms between different rotations for detecting the deformation of the blades under stress. 
The same technique could be used for monitoring any other turbines like steam turbines and turbofans of airplanes.

\section{From Step-Frequency (SF) to Frequency Modulation (FM)}

The first terrestrial interferometric radar systems for monitoring landslides or large structures used a Vector Network Analyzer (VNA) as transceiver [5], so they operated Step Frequency (SF) waveforms (see Figure 12).

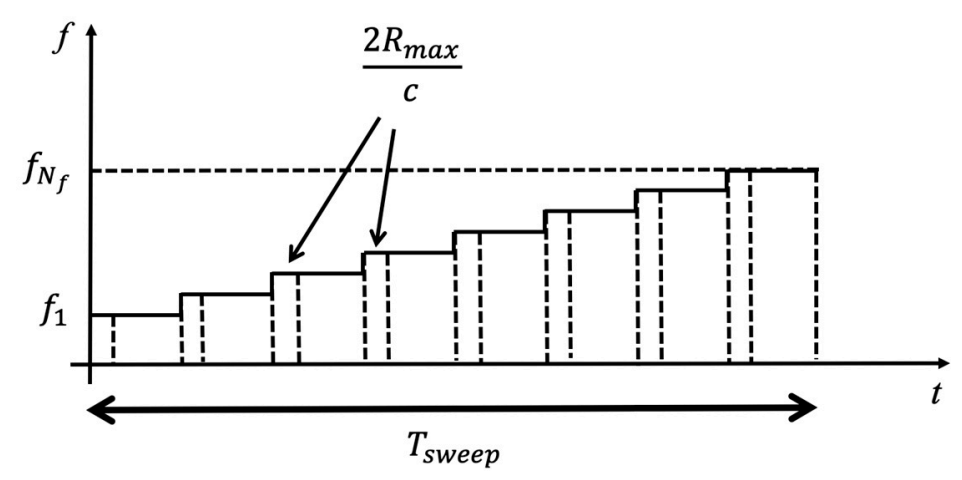

Figure 12. Step Frequency modulation.

The main drawback of SF modulation is that before changing frequency, it is necessary to wait for the time-of-flight relative to the signal from the farthest target. This is not a problem in short range applications, but for an environment of a few of $\mathrm{km}$ (e.g., in landslide or mine monitoring), the SF waveform has a sensible loss of efficiency $(\eta)$ and increases of the minimum sweep time as follow:

$$
\begin{gathered}
T_{\text {sweep }}^{(\text {min })}=\frac{2 R_{\text {max }}}{c} N_{f} \\
\eta=1-\frac{T_{\text {sweep }}^{(\text {min })}}{T_{\text {sweep }}}
\end{gathered}
$$

with $R_{\max }$ distance of the farthest detectable target, $c$ speed of light, $N_{f}$ number of frequencies of the sweep, $T_{\text {sweep }}$ sweep time. As an example, a SF radar with $R_{\max }=2000 \mathrm{~m} N_{f}=5000$, has a $T_{\text {sweep }}^{(\min )}=66 \mathrm{~ms}$. By accepting an efficiency of $50 \%$ (3dB of loss on Signal-to-Noise Ratio), it means a sweep time of $133 \mathrm{~ms}$, which could be too long in some applications. The evident solution is to use a frequency modulation (FM) transceiver [94]. The radar transmits a continuous ramp in frequency, and it is able to detect the distance of a target by the frequency difference $(\Delta f)$ between the transmitted and the received signal (see Figure 13).

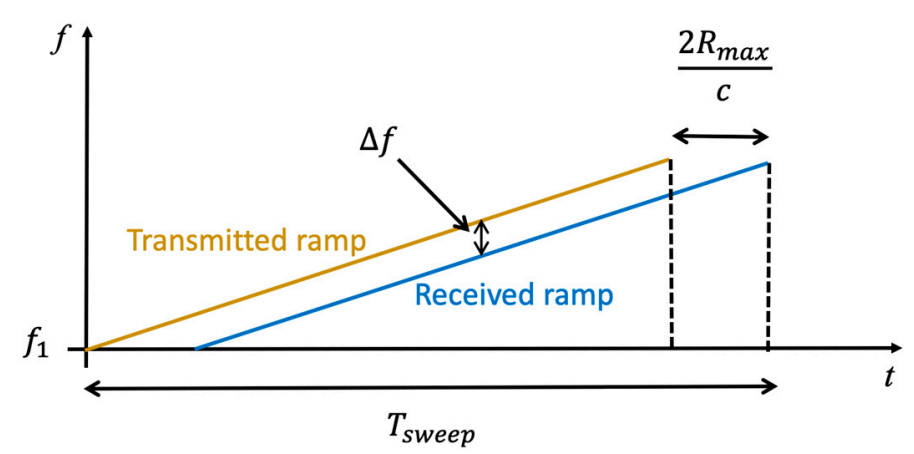

Figure 13. FM modulation. 
In this case the sweep time and the efficiency is given by:

$$
\begin{gathered}
T_{\text {sweep }} \gg \frac{2 R_{\max }}{c} \\
\eta=1-\frac{2 R_{\max }}{c} \frac{1}{T_{\text {sweep }}}
\end{gathered}
$$

Therefore, the time sweep can be much shorter than SF and the efficiency is always close to $100 \%$.

Aguasca in 2004 [27] was the first to introduce FM modulation in GBRI, followed by Wadge in 2005 [82]. The current commercial radar interferometers of IDS geo-radar [95] and meta-sensing [96] are both FM systems.

\section{Wider View Angle}

The key advantage of synthetic aperture is to reduce of a factor of two the size of the radar in comparison with the more conventional rotary radar [19]. This is probably the reason why these kinds of systems are the most popular operative modality. On the other hand, the drawback of a linear GBSAR is that its angular resolution $\left(\Delta \varphi_{\text {linear_GBSAR }}\right)$ degrades with the azimuth angle $(\varphi)$. Indeed [97]:

$$
\Delta \varphi_{\text {linear }-G B S A R} \approx \frac{\lambda}{2 L} \cos \varphi
$$

with $\lambda$ wavelength and $L$ length of the linear scan (see Figure 14a).

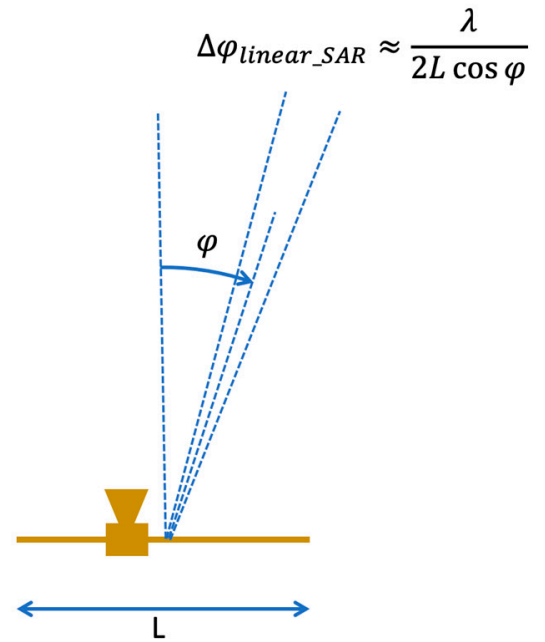

(a) Linear GBSAR

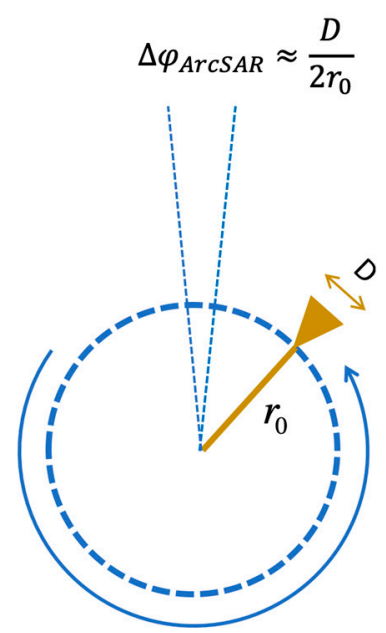

(b) ArcSAR

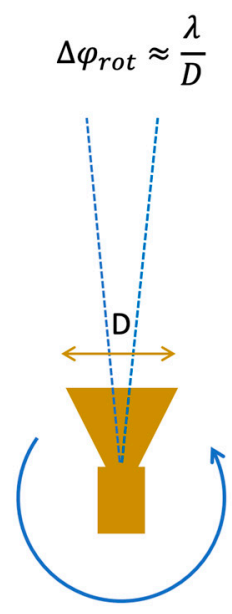

(c) Rotary radar

Figure 14. Angular resolution of Linear GBSAR (a), $\operatorname{ArcSAR}(\mathbf{b})$, and rotary radar (c).

This can be a problem in some applications, as an example, in the monitoring of open pits of circular shape when the radar is positioned close to the center and it is required to monitor the whole slope. The ArcSAR, recently developed [28,46,47], can be a solution for this kind of environment. The radar-head of an ArcSAR is moving along an arc for synthesizing an aperture. A notable feature of the ArcSAR is that its angular resolution $\left(\Delta \varphi_{\text {ArCSAR }}\right)$ is constant with azimuth and it is equal to [47]

$$
\triangle \varphi_{A r C S A R} \approx \frac{D}{2 r_{0}}
$$


with $D$ physical dimension of the rotating antenna and $r_{0}$ radius of the ArcSAR (see Figure 14b). This expression has to be compared with the standard formula for a rotary radar:

$$
\Delta \varphi_{\text {rot }} \approx \frac{\lambda}{D}
$$

with $\lambda$ wavelength (see Figure 14c). In the practice ArcSAR allows to obtain better resolution with smaller antenna. Furthermore, its resolution does not depend on operative band. Both aspects are notable.

\section{Multiple Input Multiple Output (MIMO)}

The linear GBSAR as well as any rotary radar and C-SAR need the physical movement of a radar head. The mechanical moving parts are the most prone to failures, especially in systems that operate outdoors for long periods. This is the case with the monitoring of mines and slopes. The phased array radar [98] is a possible solution. This technology is well-known and widely used in the military field. Its problem is its cost, which is too high for civil applications.

An emerging paradigm in the radar field is the MIMO (multiple input multiple output). The idea is to use a set of $\mathrm{N}_{T X}$ transmitting antennas and a separate set of $\mathrm{N}_{\mathrm{RX}}$ receiving antennas suitably positioned in space (see Figure 15).

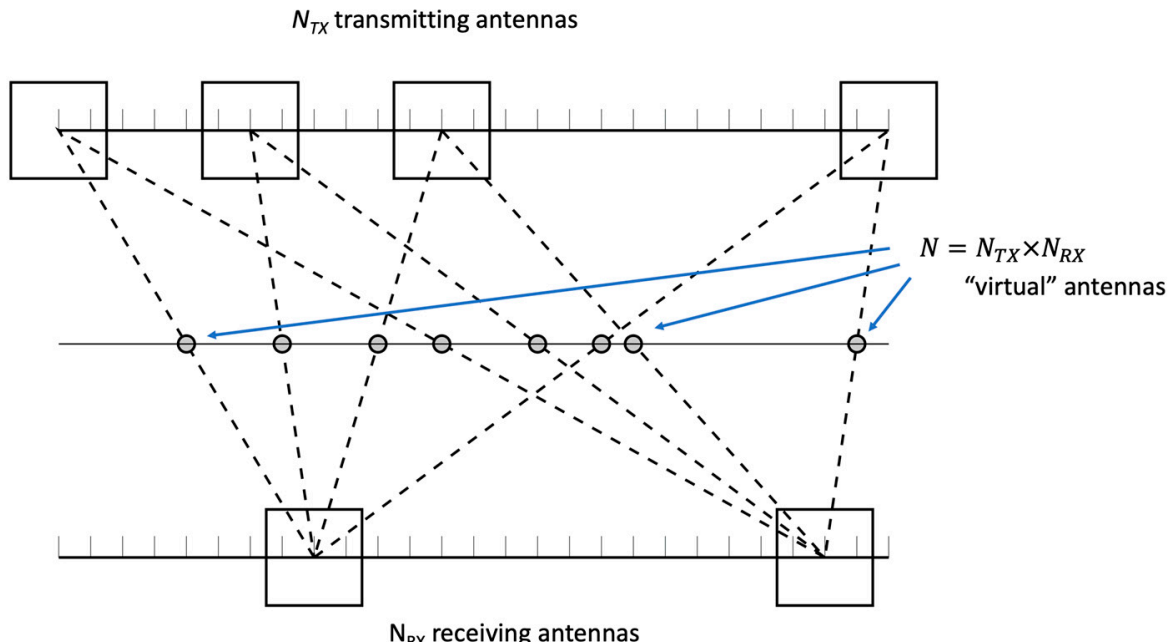

Figure 15. MIMO working principle, $\mathrm{N}_{T X}$ transmitting antennas with $\mathrm{N}_{\mathrm{RX}}$ receiving antennas are equivalent to $\mathrm{N}_{T X} \times \mathrm{N}_{\mathrm{RX}}$ "virtual" antennas.

For each transmitting antenna, all the receiving antennas are working (simultaneously or sequentially), so the number of independent measurements is given by $\mathrm{N}=\mathrm{N}_{T X} \times \mathrm{N}_{R X}$. The resulting system is a radar equivalent to a phased array that needs much less transmitting/receiving channels.

The first to propose this approach for a GBSAR was Hong in 2010 [99]. Tarchi et al. published in 2013 [20] a notable implementation of MIMO-GBSAR named MELISSA; 16 transmitting antennas operating with 16 receiving antennas, an equivalent aperture of $2.56 \mathrm{~m}$ and an acquisition time of $3.6 \mathrm{~ms}$. This very high speed of acquisition opens new interesting perspectives to this kind of radar, especially in the dynamic monitoring of buildings, towers and bridges. The MIMO approach, a radar like MELISSA, is again an equipment rather complex and expensive, that hardly can find an industrial justification in the market of monitoring equipment.

The working principle of any GBSAR (MIMO or not-MIMO) is based on dense spatial sampling (steps smaller than a quarter of wavelength) along the synthetic aperture. Compressive sensing (CS) is a recent sampling paradigm $[100,101]$ which asserts that a certain signal can be recovered from far fewer samples or measurements than a traditional methods. Its basic idea relies on the 'sparsity' of 
the signals of interest (the radar signals typically have this property [102]), and the incoherence of the sensing modality. The latter property is obtained through random sampling. The combination of MIMO and Compressive Sensing appear very attractive, i.e., the Compressive Sensing can reduces of about $40 \%$ the number of channels of a MIMO used in GBSAR applications [103]. In 2018, Pieraccini and Miccinesi [50] designed a Compressive Sensing MIMO with four transmitting antennas and four receiving antennas that have been successfully used for testing a pedestrian bridge.

\section{Detection of the Displacement Vector}

The interferometric radar detects only the displacement component along the view direction. The real displacement (of slope, building, bridge, tower, ... ) is retrieved with some hypothesis about motion. For example, in a slope, the displacement can be supposed along the gradient, in the lower deck of a bridge along the vertical axis and in a tower along the horizontal.

These suppositions can be reasonable in most cases, but there are important exceptions. As Dei et al. in 2013 [104] demonstrated, some targets, that are not at the center of the span, have a component of horizontal displacement during static monitoring of bridges. If this horizontal displacement is not considered, the results are absurd (a deck that rise when it is loaded). Figure 16 shows how this effect is in the relationship with the thickness of the deck and the position of its neutral axes.
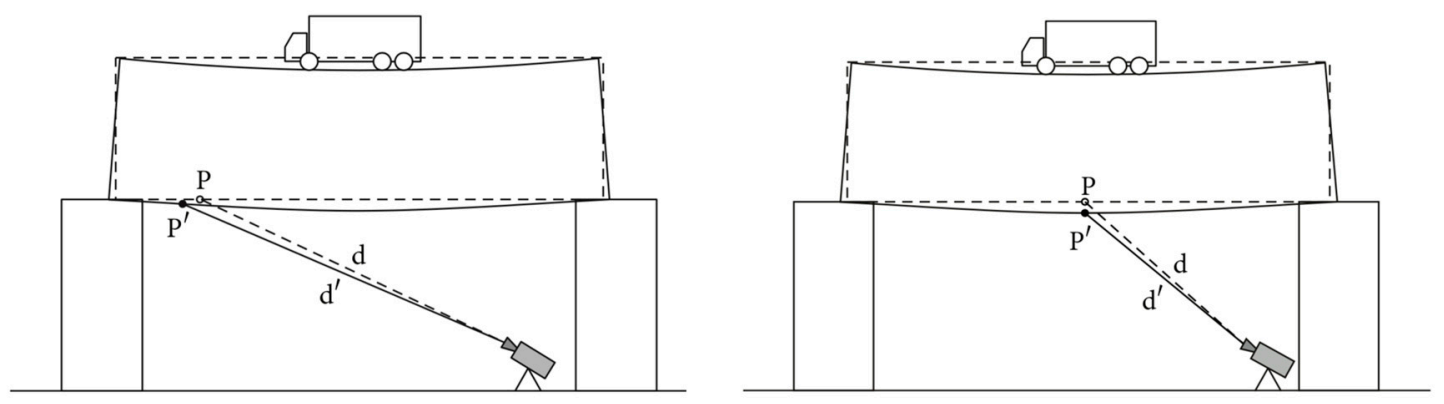

Figure 16. Effective displacement of a point $\mathrm{P}$ at an edge and close to the central span during the static test of a bridge (after [104]).

The case of slope monitoring can be more complex. For example, for detecting the real displacement pattern of Lamosano village in Italian Alps, built on a landslide, it has been necessary to combine data from both interferometric radar and lidar [62]. Unfortunately, this complex behavior of landslides is rather common.

In order to obtain more than one component of the displacement vector, in 2014, Severin et al. [105] used two GBSAR systems in different positions that monitor the same slope. In 2015, Zeng et al. [106] proposed the same principle using two MIMO. Two radar systems operating independently can be a solution, but surely is expensive and not practical. Pieraccini et al. [30], in 2017, proposed a bistatic configuration [107] that uses the bounce of the signal on a transponder for obtaining an independent component of the displacement (see Figure 17). 


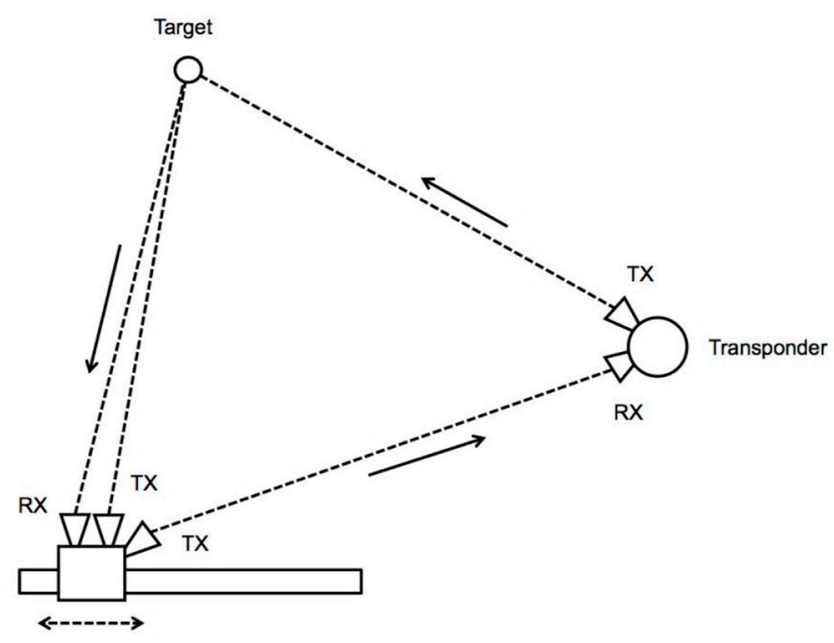

Figure 17. Bistatic GBSAR with transponder (after [30]).

Other solutions are effective only in short range; Hu et al. [108] proposed to divide the scan in two sub-apertures for obtaining two points of view with the drawback to reduce the angular resolution; Pieraccini et al. [109] proposed to use the rotation of the antenna in a vertical plane for obtaining two or three components. They tested the technique during the static test of a bridge in Florence, Italy [110].

\section{Higher Operative Frequency}

As mentioned above, C-band (4-8 GHz), X-band (8-12 GHz), amd Ku-band (12-18 GHz) all together cover about $89 \%$ of the publications. Radars at higher operative frequency are only a few. Nevertheless, the interest in these high frequency (especially W-band) is increasing. Many semiconductor producers are developing a low-cost W-band radar for automotive applications. These small radar-heads could have a great impact on radar GBRI. The high frequency allows us to design small size radar systems with the same angular resolution, but with much better range resolution with respect to the current interferometric radar systems [31,32,111,112]. Nevertheless, radars operating at these high frequencies can have problems of electronic and mechanical stability which are hard to address. Just as an example, a Ku-band radar is sensible to displacements of about $0.1 \mathrm{~mm}$, so it needs a mechanical moving system with a positioning accuracy of this order of magnitude. A W-band radar is 4.5 times more sensible, so it needs a mechanical system able to warranty $20-25 \mu \mathrm{m}$, that is a very hard specification for a system that has to operate in the field. Another important point about the use of W-band radar is the high attenuation of the atmosphere at these frequencies, which confines these radars to short-range applications.

\section{Three-Dimensional Imaging}

The idea of obtaining three-dimensional radar images using a GBSAR started with this radar itself. Already in 2000 Lopez-Sanchez [113] described a SAR migration algorithm for focusing three-dimensional images in an anechoic chamber. In the same year, Tarchi et al. [114] developed a GBSAR that obtains a 3D image of the reproduction (in scale 1:2) of an ancient façade.

Generally speaking, complex targets like buildings, tunnels, and construction works would require 3D imaging capability, but there are two practical problems. The first is the long acquisition time. With reference to Figure 18, in order to image in the three-dimensional space using a liner SAR, the radar head must scan step-by-step and line-by-line a planar surface. As an example, a fast GBSAR able to scan a line of 100 points in 5 min [115], will scan a plane of 100 lines in more than $8 \mathrm{~h}$. It means that the radar is able to detect only very slow movements. The second problem is the size and bulk of the mechanical system, which makes its deployment hard. 


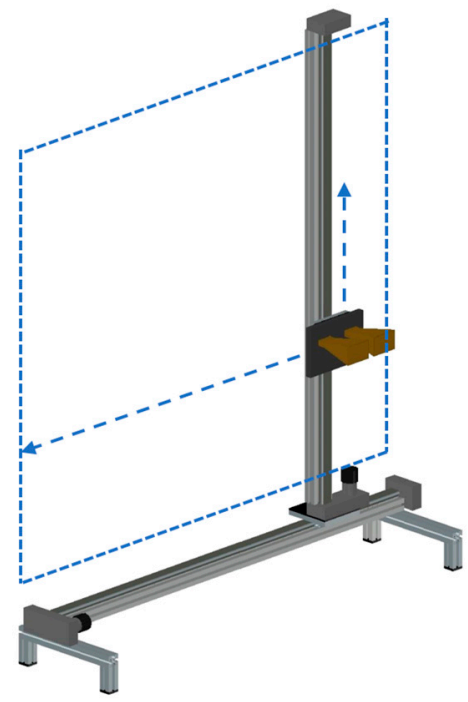

Figure 18. GBSAR with 3D imaging capability.

These are the main reasons why GBSARs with 3D imaging capability are not very popular.

The use of higher frequency (e.g., W-band) mitigates the problem of the bulky equipment, and partially even the problem of acquisition time, as the movements are smaller and, therefore, faster. The radar HYDRA [32] is a step in this direction.

A more radical solution is a two-dimensional MIMO [116], preferably based on the compressive sensing approach [117]. These are exciting developments, but they are again prototypes in a laboratory and not suitable to be used in the field.

\section{Conclusions}

In this paper the authors reviewed the vast bibliography related to ground-based/terrestrial radar interferometry by considering 415 papers from 1993 to 2018. This research shows that the linear SAR is the most common system, followed by the no-DOA systems. The majority of radar systems work in Ku-band. More than $40 \%$ of case studies are relative to landslides followed by bridges $(30 \%)$ and buildings (20\%).

What we can now ask ourselves is, where is GBRI going? We can affirm that the main development directions are forward faster radar (from SF modulation to FM modulation), radar with wider view angle (using ArcSAR configurations), MIMO, radar with capability to detect the vector of displacement and not only a single component, and small size radars operating at higher band (in Ka or W band).

Currently FM modulation and ArcSAR appear already mature for the market of monitoring equipment. Some manufacturers have products with these characteristics. MIMO GBSAR is at a good level of industrialization and probably, in a short time, we will see its diffusion. The detection of the displacement vector is again at the level of prototypes, but its usefulness is evident, and it will probably soon be established as a standard technique. Finally, interferometric radar in Ka or W band are again laboratory prototype, but we think they will have a role in the future, as well as radars with 3D imaging capability.

A final question we can address is about the long-term developments of radar interferometry. As mentioned in the introduction, the strength of GBRI is its complementarity with spaceborne SAR. Nevertheless, there is again a gap between GBRI and spaceborne SAR, that is only partially filled by airborne radars. An exciting new field of application is the use of small UAVs (unmanned aerial vehicles) as radar platforms. Some preliminary results appear very promising [118-120], but the real challenge for doing interferometry from a UAV is the accuracy of the flight trajectory that is again too poor for these kinds of applications. 
Author Contributions: Methodology, M.P. and L.M.; Writing—Original Draft Preparation, M.P.; Writing—Review \& Editing, L.M.

Funding: This research received no external funding.

Acknowledgments: We would like to thank the anonymous reviewers whose comments have greatly improved this manuscript.

Conflicts of Interest: The authors declare no conflict of interest.

\section{References}

1. Borgeaud, M.; Noll, J.; Bellini, A. Multi-temporal comparisons of ERS-1 and JERS-1 SAR data for land applications. In Proceedings of the International Geoscience and Remote Sensing Symposium (IGARSS), Pasadena, CA, USA, 8-12 August 1994; Volume 3, pp. 1603-1605.

2. Srivastava, S.K.; Lukowski, T.I.; Gray, R.B.; Shepherd, N.W.; Hawkins, R.K. RADARSAT: Image quality management and performance results. In Proceedings of the Canadian Conference on Electrical and Computer Engineering, Calgary, AB, Canada, 26-29 May 1996; Volume 1, pp. 21-23.

3. Massonnet, D.; Rossi, M.; Carmona, C.; Adragna, F.; Peltzer, G.; Feigl, K.; Rabaute, T. The displacement field of the Landers earthquake mapped by radar interferometry. Nature 1993, 364, 138-142. [CrossRef]

4. Atzori, S.; Hunstad, I.; Chini, M.; Salvi, S.; Tolomei, C.; Bignami, C.; Stramondo, S.; Trasatti, E.; Antonioli, A.; Boschi, E. Finite fault inversion of DInSAR coseismic displacement of the 2009 L'Aquila earthquake (central Italy). Geophys. Res. Lett. 2009, 36. [CrossRef]

5. Tarchi, D.; Ohlmer, E.; Sieber, A. Monitoring of structural changes by radar interferometry. Res. Nondestruct. Eval. 1997, 9, 213-225.

6. Tarchi, D.; Rudolf, H.; Luzi, G.; Chiarantini, L.; Coppo, P.; Sieber, A.J. SAR interferometry for structural changes detection: A demonstration test on a dam. In Proceedings of the International Geoscience and Remote Sensing Symposium (IGARSS), Hamburg, Germany, 28 June-2 July 1999; Volume 3, pp. 1522-1524.

7. Pieraccini, M.; Tarchi, D.; Rudolf, H.; Leva, D.; Luzi, G.; Bartoli, G.; Atzeni, C. Structural static testing by interferometric synthetic radar. NDT E Int. 2000, 33, 565-570. [CrossRef]

8. Tarchi, D.; Casagli, N.; Fanti, R.; Leva, D.D.; Luzi, G.; Pasuto, A.; Pieraccini, M.; Silvano, S. Landslide monitoring by using ground-based SAR interferometry: An example of application to the Tessina landslide in Italy. Eng. Geol. 2003, 68, 15-30. [CrossRef]

9. Farr, T.G.; Rosen, P.A.; Caro, E.; Crippen, R.; Duren, R.; Hensley, S.; Kobrick, M.; Paller, M.; Rodriguez, E.; Roth, L.; et al. The shuttle radar topography mission. Rev. Geophys. 2007, 45. [CrossRef]

10. Noferini, L.; Pieraccini, M.; Mecatti, D.; Macaluso, G.; Luzi, G.; Atzeni, C. DEM by Ground-Based SAR Interferometry. IEEE Geosci. Remote Sens. Lett. 2007, 4, 659-663. [CrossRef]

11. Carlà, T.; Tofani, V.; Lombardi, L.; Raspini, F.; Bianchini, S.; Bertolo, D.; Thuegaz, P.; Casagli, N. Combination of GNSS, satellite InSAR, and GBInSAR remote sensing monitoring to improve the understanding of a large landslide in high alpine environment. Geomorphology 2019, 335, 62-75. [CrossRef]

12. Corsini, A.; Farina, P.; Antonello, G.; Barbieri, M.; Casagli, N.; Coren, F.; Guerri, L.; Ronchetti, F.; Sterzai, P.; Tarchi, D. Space-borne and ground-based SAR interferometry as tools for landslide hazard management in civil protection. Int. J. Remote Sens. 2006, 27, 2351-2369. [CrossRef]

13. Han, H.; Lee, H. Motion of Campbell glacier, east antarctica, observed by satellite and ground-based interferometric synthetic aperture radar. In Proceedings of the APSAR 2011 3rd International Asia-Pacific Conference on Synthetic Aperture Radar, Seoul, Korea, 26-30 September 2011; p. 4.

14. Pieraccini, M. Monitoring of civil infrastructures by interferometric radar: A review. Sci. World J. 2013, 2013, 786961. [CrossRef]

15. Caduff, R.; Schlunegger, F.; Kos, A.; Wiesmann, A. A review of terrestrial radar interferometry for measuring surface change in the geosciences. Earth Surf. Process. Landf. 2015, 40, 208-228. [CrossRef]

16. Monserrat, O.; Crosetto, M.; Luzi, G. A review of ground-based SAR interferometry for deformation measurement. ISPRS J. Photogramm. Remote Sens. 2014, 93, 40-48. [CrossRef]

17. Pieraccini, M.; Fratini, M.; Parrini, F.; Atzeni, C. Dynamic Monitoring of Bridges Using a High-Speed Coherent Radar. IEEE Trans. Geosci. Remote Sens. 2006, 44, 3284-3288. [CrossRef] 
18. Reeves, B.A.; Stickley, G.F.; Noon, D.A.; Longstaff, I.D. Developments in monitoring mine slope stability using radar interferometry. In Proceedings of the IGARSS IEEE 2000 International Geoscience and Remote Sensing Symposium. Taking the Pulse of the Planet: The Role of Remote Sensing in Managing the Environment. Proceedings (Cat. No.00CH37120), Honolulu, HI, USA, 24-28 July 2000; Volume 5, pp. 2325-2327.

19. Pieraccini, M. Real Beam vs. Synthetic aperture radar for slope monitoring. In Proceedings of the Progress in Electromagnetics Research Symposium, Taipei, Taiwan, 25-28 March 2013; pp. 1627-1632.

20. Tarchi, D.; Oliveri, F.; Sammartino, P.F. MIMO Radar and Ground-Based SAR Imaging Systems: Equivalent Approaches for Remote Sensing. IEEE Trans. Geosci. Remote Sens. 2013, 51, 425-435. [CrossRef]

21. Lukin, K.; Mogila, A.; Vyplavin, P.; Galati, G.; Pavan, G. Novel concepts for surface movement radar design. Int. J. Microw. Wirel. Technol. 2009, 1, 163. [CrossRef]

22. Pieraccini, M.; Luzi, G.; Mecatti, D.; Fratini, M.; Noferini, L.; Carissimi, L.; Franchioni, G.; Atzeni, C. Remote sensing of building structural displacements using a microwave interferometer with imaging capability. NDT E Int. 2004, 37, 545-550. [CrossRef]

23. Atzeni, C.; Bicci, A.; Dei, D.; Fratini, M.; Pieraccini, M. Remote Survey of the Leaning Tower of Pisa by Interferometric Sensing. IEEE Geosci. Remote Sens. Lett. 2010, 7, 185-189. [CrossRef]

24. Luzi, G.; Pieraccini, M.; Mecatti, D.; Noferini, L.; Macaluso, G.; Tamburini, A.; Atzeni, C. Monitoring of an Alpine Glacier by Means of Ground-Based SAR Interferometry. IEEE Geosci. Remote Sens. Lett. 2007, 4, 495-499. [CrossRef]

25. Pieraccini, M.; Betti, M.; Forcellini, D.; Dei, D.; Papi, F.; Bartoli, G.; Facchini, L.; Corazzi, R.; Kovacevic, V.C. Radar detection of pedestrian-induced vibrations on Michelangelo's David. PLoS ONE 2017, 12, e0174480.

26. Antonello, G.; Fortuny, J.; Tarchi, D.; Casagli, N.; Del Ventisette, C.; Guerri, L.; Luzi, G.; Mugnai, F.; Leva, D. Microwave interferometric sensors as a tool for space and time analysis of active volcano deformations: The Stromboli case. In Proceedings of the 2008 Second Workshop on Use of Remote Sensing Techniques for Monitoring Volcanoes and Seismogenic Areas, Napoli, Italy, 11-14 November 2008; pp. 1-6.

27. Aguasca, A.; Broquetas, A.; Mallorque, J.J.; Fabregas, X. A solid state L to X-band flexible ground-based SAR system for continuous monitoring applications. In Proceedings of the IGARSS '04 IEEE International IEEE International IEEE International Geoscience and Remote Sensing Symposium, Anchorage, AK, USA, 20-24 September 2004; Volume 2, pp. 757-760.

28. Lee, H.; Lee, J.-H.; Kim, K.-E.; Sung, N.-H.; Cho, S.-J. Development of a Truck-Mounted Arc-Scanning Synthetic Aperture Radar. IEEE Trans. Geosci. Remote Sens. 2014, 52, 2773-2779. [CrossRef]

29. Hu, C.; Wang, J.; Tian, W.; Zeng, T.; Wang, R. Design and Imaging of Ground-Based Multiple-Input Multiple-Output Synthetic Aperture Radar (MIMO SAR) with Non-Collinear Arrays. Sensors 2017, 17, 598. [CrossRef]

30. Pieraccini, M.; Miccinesi, L.; Rojhani, N. A GBSAR Operating in Monostatic and Bistatic Modalities for Retrieving the Displacement Vector. IEEE Geosci. Remote Sens. Lett. 2017, 14, 1494-1498. [CrossRef]

31. Martínez, A.; Aguasca, A.; Lort, M.; Broquetas, A. Micrometric deformation imaging at W-Band with GBSAR. Eur. J. Remote Sens. 2016, 49, 719-733. [CrossRef]

32. D'Aria, D.; Amoroso, G.; Bicci, A.; Coppi, F.; Cecchetti, M.; Rossi, M.; Falcone, P. Advanced tomographic tool for HYDRA radar system. In Proceedings of the European Conference on Synthetic Aperture Radar, EUSAR, Aachen, Germany, 4-7 June 2018; Volume 2018, pp. 484-486.

33. Pieraccini, M.; Luzi, G.; Atzeni, C. Terrain mapping by ground-based interferometric radar. IEEE Trans. Geosci. Remote Sens. 2001, 39, 2176-2181. [CrossRef]

34. Iannini, L.; Monti Guarnieri, A. Atmospheric phase screen in ground-based radar: Statistics and compensation. IEEE Geosci. Remote Sens. Lett. 2011, 8, 537-541. [CrossRef]

35. Iglesias, R.; Fabregas, X.; Aguasca, A.; Mallorqui, J.J.; Lopez-Martinez, C.; Gili, J.A.; Corominas, J. Atmospheric phase screen compensation in ground-based sar with a multiple-regression model over mountainous regions. IEEE Trans. Geosci. Remote Sens. 2014, 52, 2436-2449. [CrossRef]

36. Zhang, X.; Lu, B.-Y.; Song, Q.; Leng, M. Atmospheric Disturbance Correction in Ground-Based SAR Differential Interferometry. In Proceedings of the 2011 IEEE CIE International Conference on Radar, Chengdu, China, 24-27 October 2011; Volume 2, pp. 1574-1577.

37. Noferini, L.; Pieraccini, M.; Mecatti, D.; Luzi, G.; Atzeni, C.; Tamburini, A.; Broccolato, M. Permanent scatterers analysis for atmospheric correction in ground-based SAR interferometry. IEEE Trans. Geosci. Remote Sens. 2005, 43, 1459-1470. [CrossRef] 
38. Moreira, A.; Prats-Iraola, P.; Younis, M.; Krieger, G.; Hajnsek, I.; Papathanassiou, K.P. A tutorial on synthetic aperture radar. IEEE Geosci. Remote Sens. Mag. 2013, 1, 6-43. [CrossRef]

39. Grazzini, G.; Pieraccini, M.; Dei, D.; Atzeni, C. Simple microwave sensor for remote detection of structural vibration. Electron. Lett. 2009, 45, 567. [CrossRef]

40. Richards, M.A.; Scheer, J.A.; Holm, W.A. Principles of Modern Radar: Basic Principles; SciTech Publishing: Raleigh, NC, USA, 2010.

41. Werner, C.; Strozzi, T.; Wiesmann, A.; Wegmulle, U. A real-aperture radar for ground-based differential interferometry. In Proceedings of the International Geoscience and Remote Sensing Symposium (IGARSS), Boston, MA, USA, 8-11 July 2008; Volume 3, pp. III210-III213.

42. Franceschetti, G.; Lanari, R. Synthetic Aperture Radar Processing, 1st ed.; CRC Press: Boca Raton, FL, USA, 2018; ISBN 978-0-203-73748-4.

43. Li, J.; Stoica, P. (Eds.) MIMO Radar Signal Processing; J. Wiley \& Sons: Hoboken, NJ, USA, 2009; ISBN 978-0-470-17898-0.

44. Farrar, C.R.; Darling, T.W.; Migliori, A.; Baker, W.E. Microwave interferometers for non-contact vibration measurements on large structures. Mech. Syst. Signal Process. 1999, 13, 241-253. [CrossRef]

45. Werner, C.; Strozzi, T.; Wiesmann, A.; Wegmüller, U. GAMMA'S PORTABLE RADAR INTERFEROMETER. In Proceedings of the 13th FIG Symposium on Deformation Measurement Analysis, Lisbon, Portugal, 12-15 May 2008; p. 10.

46. Luo, Y.; Song, H.; Wang, R.; Deng, Y.; Zhao, F.; Xu, Z. Arc FMCW sar and applications in ground monitoring. IEEE Trans. Geosci. Remote Sens. 2014, 52, 5989-5998. [CrossRef]

47. Pieraccini, M.; Miccinesi, L. ArcSAR: Theory, Simulations, and Experimental Verification. IEEE Trans. Microw. Theory Tech. 2017, 65, 293-301. [CrossRef]

48. Available online: https://idsgeoradar.com (accessed on 29 April 2019).

49. Available online: https://www.groundprobe.com (accessed on 29 April 2019).

50. Pieraccini, M.; Miccinesi, L. An Interferometric MIMO Radar for Bridge Monitoring. IEEE Geosci. Remote Sens. Lett. 2019, 1-5 (Early Access from https://ieeexplore.ieee.org). [CrossRef]

51. Martinez-Vazquez, A.; Fortuny-Guasch, J.; Gruber, U. Monitoring of the snow cover. EARSeL eProc. 2005, 4, 171-178.

52. Luzi, G.; Noferini, L.; Mecatti, D.; Macaluso, G.; Pieraccini, M.; Atzeni, C.; Schaffhauser, A.; Fromm, R.; Nagler, T. Using a Ground-Based SAR Interferometer and a Terrestrial Laser Scanner to Monitor a Snow-Covered Slope: Results from an Experimental Data Collection in Tyrol (Austria). IEEE Trans. Geosci. Remote Sens. 2009, 47, 382-393. [CrossRef]

53. Martinez-Vazquez, A.; Fortuny-Guasch, J. A GB-SAR Processor for Snow Avalanche Identification. IEEE Trans. Geosci. Remote Sens. 2008, 46, 3948-3956. [CrossRef]

54. Hasch, J.; Topak, E.; Schnabel, R.; Zwick, T.; Weigel, R.; Waldschmidt, C. Millimeter-wave technology for automotive radar sensors in the $77 \mathrm{GHz}$ frequency band. IEEE Trans. Microw. Theory Tech. 2012, 60, 845-860. [CrossRef]

55. Intrieri, E.; Gigli, G.; Nocentini, M.; Lombardi, L.; Mugnai, F.; Fidolini, F.; Casagli, N. Sinkhole monitoring and early warning: An experimental and successful GB-InSAR application. Geomorphology 2015, 241, 304-314. [CrossRef]

56. Lombardi, L.; Nocentini, M.; Frodella, W.; Nolesini, T.; Bardi, F.; Intrieri, E.; Carlà, T.; Solari, L.; Dotta, G.; Ferrigno, F.; et al. The Calatabiano landslide (southern Italy): Preliminary GB-InSAR monitoring data and remote 3D mapping. Landslides 2017, 14, 685-696. [CrossRef]

57. Frodella, W.; Ciampalini, A.; Bardi, F.; Salvatici, T.; Di Traglia, F.; Basile, G.; Casagli, N. A method for assessing and managing landslide residual hazard in urban areas. Landslides 2018, 15, 183-197. [CrossRef]

58. Noferini, L.; Pieraccini, M.; Luzi, G.; Mecatti, D.; Macaluso, G.; Atzeni, C. Ground-based radar interferometry for monitoring unstable slopes. In Proceedings of the International Geoscience and Remote Sensing Symposium (IGARSS), Denver, CO, USA, 31 July-4 August 2006; pp. 4088-4091.

59. Harries, N.; Noon, D.; Pritchett, H.; Bates, D. Slope Stability Radar for Managing Rock Fall Risks in Open Cut Mines. In Proceedings of the roceedings of the 3rd CANUS Rock Mechanics Symposium, Toronto, ON, Canada, 9-15 May 2009; p. 8. 
60. Bardi, F.; Frodella, W.; Ciampalini, A.; Bianchini, S.; Del Ventisette, C.; Gigli, G.; Fanti, R.; Moretti, S.; Basile, G.; Casagli, N. Integration between ground based and satellite SAR data in landslide mapping: The San Fratello case study. Geomorphology 2014, 223, 45-60. [CrossRef]

61. Serrano-Juan, A.; Vázquez-Suñè, E.; Monserrat, O.; Crosetto, M.; Hoffmann, C.; Ledesma, A.; Criollo, R.; Pujades, E.; Velasco, V.; Garcia-Gil, A.; et al. Gb-SAR interferometry displacement measurements during dewatering in construction works. Case of La Sagrera railway station in Barcelona, Spain. Eng. Geol. 2016, 205, 104-115. [CrossRef]

62. Pieraccini, M.; Noferini, L.; Mecatti, D.; Atzeni, C.; Teza, G.; Galgaro, A.; Zaltron, N. Integration of Radar Interferometry and Laser Scanning for Remote Monitoring of an Urban Site Built on a Sliding Slope. IEEE Trans. Geosci. Remote Sens. 2006, 44, 2335-2342. [CrossRef]

63. Pipia, L.; Fabregas, X.; Aguasca, A.; Lopez-Martinez, C.; Duque, S.; Mallorqui, J.J.; Marturia, J. Polarimetric Differential SAR Interferometry: First Results with Ground-Based Measurements. IEEE Geosci. Remote Sens. Lett. 2009, 6, 167-171. [CrossRef]

64. Luzi, G.; Crosetto, M.; Cuevas-González, M. A radar-based monitoring of the Collserola tower (Barcelona). Mech. Syst. Signal Process. 2014, 49, 234-248. [CrossRef]

65. Mecatti, D.; Noferini, L.; Macaluso, G.; Pieraccini, M.; Luzi, G.; Atzeni, C.; Tamburini, A. Remote sensing of glacier by ground-based radar interferometry. In Proceedings of the International Geoscience and Remote Sensing Symposium (IGARSS), Barcelona, Spain, 23-27 July 2007; pp. 4501-4504.

66. Calvari, S.; Intrieri, E.; Di Traglia, F.; Bonaccorso, A.; Casagli, N.; Cristaldi, A. Monitoring crater-wall collapse at active volcanoes: A study of the 12 January 2013 event at Stromboli. Bull. Volcanol. 2016, 78, 39. [CrossRef]

67. Oerlemans, J.; Anderson, B.; Hubbard, A.; Huybrechts, P.; Jóhannesson, T.; Knap, W.H.; Schmeits, M.; Stroeven, A.P.; Van De Wal, R.S.W.; Wallinga, J.; et al. Modelling the response of glaciers to climate warming. Clim. Dyn. 1998, 14, 267-274. [CrossRef]

68. Chapuis, A.; Rolstad, C.; Norland, R. Interpretation of amplitude data from a ground-based radar in combination with terrestrial photogrammetry and visual observations for calving monitoring of Kronebreen, Svalbard. Ann. Glaciol. 2010, 51, 34-40. [CrossRef]

69. Xie, S.; Dixon, T.H.; Voytenko, D.; Holland, D.M.; Holland, D.; Zheng, T. Precursor motion to iceberg calving at Jakobshavn Isbræ, Greenland, observed with terrestrial radar interferometry. J. Glaciol. 2016, 62, 1134-1142. [CrossRef]

70. Pieraccini, M. Extensive Measurement Campaign Using Interferometric Radar. J. Perform. Constr. Facil. 2017, 31, 04016113. [CrossRef]

71. Pieraccini, M.; Fratini, M.; Dei, D.; Atzeni, C. Structural testing of Historical Heritage Site Towers by microwave remote sensing. J. Cult. Herit. 2009, 10, 174-182. [CrossRef]

72. Fratini, M.; Pieraccini, M.; Atzeni, C.; Betti, M.; Bartoli, G. Assessment of vibration reduction on the Baptistery of San Giovanni in Florence (Italy) after vehicular traffic block. J. Cult. Herit. 2011, 12, 323-328. [CrossRef]

73. Tapete, D.; Casagli, N.; Luzi, G.; Fanti, R.; Gigli, G.; Leva, D. Integrating radar and laser-based remote sensing techniques for monitoring structural deformation of archaeological monuments. J. Archaeol. Sci. 2013, 40, 176-189. [CrossRef]

74. Pratesi, F.; Nolesini, T.; Bianchini, S.; Leva, D.; Lombardi, L.; Fanti, R.; Casagli, N. Early Warning GBInSAR-Based Method for Monitoring Volterra (Tuscany, Italy) City Walls. IEEE J. Sel. Top. Appl. Earth Obs. Remote Sens. 2015, 8, 1753-1762. [CrossRef]

75. Pieraccini, M.; Dei, D.; Betti, M.; Bartoli, G.; Tucci, G.; Guardini, N. Dynamic identification of historic masonry towers through an expeditious and no-contact approach: Application to the "Torre del Mangia" in Siena (Italy). J. Cult. Herit. 2014, 15, 275-282. [CrossRef]

76. Castellano, A.; Fraddosio, A.; Martorano, F.; Mininno, G.; Paparella, F.; Piccioni, M.D. Structural health monitoring of a historic masonry bell tower by radar interferometric measurements. In Proceedings of the 2018 IEEE Workshop on Environmental, Energy, and Structural Monitoring Systems (EESMS), Salerno, Italy, 21-22 June 2018; pp. 1-6.

77. Di Traglia, F.; Nolesini, T.; Ciampalini, A.; Solari, L.; Frodella, W.; Bellotti, F.; Fumagalli, A.; De Rosa, G.; Casagli, N. Tracking morphological changes and slope instability using spaceborne and ground-based SAR data. Geomorphology 2018, 300, 95-112. [CrossRef] 
78. Nolesini, T.; Di Traglia, F.; Del Ventisette, C.; Moretti, S.; Casagli, N. Deformations and slope instability on Stromboli volcano: Integration of GBInSAR data and analog modeling. Geomorphology 2013, 180-181, 242-254. [CrossRef]

79. Di Traglia, F.; Intrieri, E.; Nolesini, T.; Bardi, F.; Del Ventisette, C.; Ferrigno, F.; Frangioni, S.; Frodella, W.; Gigli, G.; Lotti, A.; et al. The ground-based InSAR monitoring system at Stromboli volcano: Linking changes in displacement rate and intensity of persistent volcanic activity. Bull. Volcanol. 2014, 76, 1-18. [CrossRef]

80. Di Traglia, F.; Nolesini, T.; Solari, L.; Ciampalini, A.; Frodella, W.; Steri, D.; Allotta, B.; Rindi, A.; Marini, L.; Monni, N.; et al. Lava delta deformation as a proxy for submarine slope instability. Earth Planet. Sci. Lett. 2018, 488, 46-58. [CrossRef]

81. Intrieri, E.; Di Traglia, F.; Del Ventisette, C.; Gigli, G.; Mugnai, F.; Luzi, G.; Casagli, N. Flank instability of Stromboli volcano (Aeolian Islands, Southern Italy): Integration of GB-InSAR and geomorphological observations. Geomorphology 2013, 201, 60-69. [CrossRef]

82. Wadge, G.; Macfarlane, D.G.; Robertson, D.A.; Hale, A.J.; Pinkerton, H.; Burrell, R.V.; Norton, G.E.; James, M.R. AVTIS: A novel millimetre-wave ground based instrument for volcano remote sensing. J. Volcanol. Geotherm. Res. 2005, 146, 307-318. [CrossRef]

83. Kuraoka, S.; Nakashima, Y.; Doke, R.; Mannen, K. Monitoring ground deformation of eruption center by ground-based interferometric synthetic aperture radar (GB-InSAR): A case study during the 2015 phreatic eruption of Hakone volcano. Earth Planets Space 2018, 70, 181. [CrossRef]

84. Noferini, L.; Pieraccini, M.; Luzi, G.; Mecatti, D.; Macaluso, G.; Atzeni, C. Ground-based radar interferometry for terrain mapping. In Proceedings of the International Geoscience and Remote Sensing Symposium (IGARSS), Denver, CO, USA, 31 July-4 August 2006; pp. 2569-2572.

85. Schaffhauser, A.; Adams, M.; Fromm, R.; Jörg, P.; Luzi, G.; Noferini, L.; Sailer, R. Remote sensing based retrieval of snow cover properties. Cold Reg. Sci. Technol. 2008, 54, 164-175. [CrossRef]

86. Zhou, Z.-S.; Boerner, W.-M.; Sato, M. Development of a ground-based polarimetric broadband SAR system for noninvasive ground-truth validation in vegetation monitoring. IEEE Trans. Geosci. Remote Sens. 2004, 42, 1803-1810. [CrossRef]

87. Bukenya, P.; Moyo, P.; Beushausen, H.; Oosthuizen, C. Health monitoring of concrete dams: A literature review. J. Civ. Struct. Health Monit. 2014, 4, 235-244. [CrossRef]

88. Luojus, K.P.; Pulliainen, J.T.; Metsämäki, S.J.; Hallikainen, M.T. Snow-covered area estimation using satellite radar wide-swath images. IEEE Trans. Geosci. Remote Sens. 2007, 45, 978-988. [CrossRef]

89. Broussolle, J.; Kyovtorov, V.; Basso, M.; Ferraro Di Silvi, E.; Castiglione, G.; Figueiredo Morgado, J.; Giuliani, R.; Oliveri, F.; Sammartino, P.F.; Tarchi, D. MELISSA, a new class of ground based InSAR system. An example of application in support to the Costa Concordia emergency. ISPRS J. Photogramm. Remote Sens. 2014, 91, 50-58. [CrossRef]

90. Nico, G.; Cifarelli, G.; Miccoli, G.; Soccodato, F.; Feng, W.; Sato, M.; Miliziano, S.; Marini, M. Measurement of Pier Deformation Patterns by Ground-Based SAR Interferometry: Application to a Bollard Pull Trial. IEEE J. Ocean. Eng. 2018, 43, 822-829. [CrossRef]

91. Li, C.J.; Bhalla, R.; Ling, H. Investigation of the Dynamic Radar Signatures of a Vertical-Axis Wind Turbine. IEEE Antennas Wirel. Propag. Lett. 2015, 14, 763-766. [CrossRef]

92. Munoz-Ferreras, J.-M.; Peng, Z.; Tang, Y.; Gomez-Garcia, R.; Liang, D.; Li, C. A Step Forward Towards Radar Sensor Networks for Structural Health Monitoring of Wind Turbines. In Proceedings of the 2016 IEEE Radio and Wireless Symposium (RWS), Austin, TX, USA, 24-27 January 2016.

93. Li, C.J.; Yang, S.-T.; Ling, H. In-Situ ISAR Imaging of Wind Turbines. IEEE Trans. Antennas Propag. 2016, 64, 3587-3596. [CrossRef]

94. Smolskiy, S.M.; Komarov, I.V. Fundamentals of Short-Range FM Radar; Komarov, I.V., Smolskiy, S.M., Eds.; Artech House: Boston, MA, USA; London, UK, 2003; ISBN 978-1-58053-110-8.

95. Available online: https://idsgeoradar.com/products/interferometric-radar/ibis-fm (accessed on 20 April 2019).

96. Placidi, S.; Meta, A.; Testa, L.; Rodelsperger, S. Monitoring structures with FastGBSAR. In Proceedings of the 2015 IEEE Radar Conference, Johannesburg, South Africa, 27-30 October 2015; pp. 435-439.

97. Mensa, D.L. High Resolution Radar Imaging; Mensa, D.L., Ed.; Artech House: Dedham, MA, USA, 1981; ISBN 978-0-89006-109-1.

98. Jeffrey, T. Phased-Array Radar Design: Application of Radar Fundamentals; Scitech Publishing: Raleigh, NC, USA, 2009. 
99. Hong, W.; Tan, W.; Wang, Y.; Wu, Y. Development and Experiments of Ground-Based SAR in IECAS for Advanced SAR Imaging Technique Validation. In Proceedings of the EUSAR 2010, Aachen, Germany, 7-10 June 2010; p. 4.

100. Candes, E.J.; Wakin, M.B. An introduction to compressive sampling: A sensing/sampling paradigm that goes against the common knowledge in data acquisition. IEEE Signal Process. Mag. 2008, 25, 21-30. [CrossRef]

101. Massa, A.; Rocca, P.; Oliveri, G. Compressive sensing in electromagnetics-A review. IEEE Antennas Propag. Mag. 2015, 57, 224-238. [CrossRef]

102. Hadi, M.A.; Alshebeili, S.; Jamil, K.; El-Samie, F.E.A. Compressive sensing applied to radar systems: An overview. Signal Image Video Process. 2015, 9, 25-39. [CrossRef]

103. Pieraccini, M.; Rojhani, N.; Miccinesi, L. Compressive Sensing for Ground Based Synthetic Aperture Radar. Remote Sens. 2018, 10, 1960. [CrossRef]

104. Dei, D.; Mecatti, D.; Pieraccini, M. Static Testing of a Bridge Using an Interferometric Radar: The Case Study of "Ponte degli Alpini", Belluno, Italy. Sci. World J. 2013, 2013, 1-7. [CrossRef]

105. Severin, J.; Eberhardt, E.; Leoni, L.; Fortin, S. Development and application of a pseudo-3D pit slope displacement map derived from ground-based radar. Eng. Geol. 2014, 181, 202-211. [CrossRef]

106. Zeng, T.; Mao, C.; Hu, C.; Yang, X.; Tian, W. Multi-static MIMO-SAR three dimensional deformation measurement system. In Proceedings of the 2015 IEEE 5th Asia-Pacific Conference on Synthetic Aperture Radar (APSAR), Singapore, 1-4 September 2015; pp. 297-301.

107. Cherniakov, M. Bistatic Radar: Emerging Technology; John Wiley \& Sons: Hoboken, NJ, USA, 2008; ISBN 978-0-470-98574-8.

108. Hu, C.; Deng, Y.; Wang, R.; Tian, W.; Zeng, T. Two-Dimensional Deformation Measurement Based on Multiple Aperture Interferometry in Gb-SAR. IEEE Geosci. Remote Sens. Lett. 2017, 14, 208-212. [CrossRef]

109. Pieraccini, M.; Papi, F.; Rocchio, S. Interferometric RotoSAR. Electron. Lett. 2015, 51, 1451-1453. [CrossRef]

110. Pieraccini, M.; Miccinesi, L. RotoSAR for monitoring bridges. In Proceedings of the European Radar Conference, EURAD 2017, Nuremberg, Germany, 11-13 October 2017; pp. 311-314.

111. Yigit, E.; Demirci, S.; Unal, A.; Ozdemir, C.; Vertiy, A. Millimeter-wave ground-based synthetic aperture radar imaging for foreign object debris detection: Experimental studies at short ranges. J. Infrared Millim. Terahertz Waves 2012, 33, 1227-1238. [CrossRef]

112. Martínez, A.; Lort, M.; Aguasca, A.; Broquetas, A. Submillimetric motion detection with a $94 \mathrm{GHz}$ ground based Synthetic Aperture Radar. In Proceedings of the IET Conference Publications, Hangzhou, China, 14-16 October 2015; Volume 2015.

113. Lopez-Sanchez, J.M.; Fortuny-Guasch, J. 3-D radar imaging using range migration techniques. IEEE Trans. Antennas Propag. 2000, 48, 728-737. [CrossRef]

114. Tarchi, D.; Rudolf, H.; Pieraccini, M.; Atzeni, C. Remote monitoring of buildings using a ground-based SAR: Application to cultural heritage survey. Int. J. Remote Sens. 2000, 21, 3545-3551. [CrossRef]

115. Frukacz, M.; Wieser, A. On the impact of rockfall catch fences on ground-based radar interferometry. Landslides 2017, 14, 1431-1440. [CrossRef]

116. Ma, C.; Yeo, T.S.; Zhao, Y.; Feng, J. MIMO radar 3D imaging based on combined amplitude and total variation cost function with sequential order one negative exponential form. IEEE Trans. Image Process. 2014, 23, 2168-2183. [CrossRef]

117. Karlina, R.; Sato, M. Compressive sensing applied to imaging by ground-based polarimetric SAR. In Proceedings of the International Geoscience and Remote Sensing Symposium (IGARSS), Vancouver, BC, Canada, 24-29 July 2011; pp. 2861-2864.

118. Zaugg, E.C.; Hudson, D.L.; Long, D.G. The BYU $\mu$ SAR: A Small, Student-Built SAR for UAV Operation. In Proceedings of the 2006 IEEE International Symposium on Geoscience and Remote Sensing, Denver, CO, USA, 31 July-4 August 2006. 
119. Essen, H.; Johannes, W.; Stanko, S.; Sommer, R.; Wahlen, A.; Wilcke, J. High Resolution W-Band UAV SAR. In Proceedings of the 2012 IEEE International Geoscience and Remote Sensing Symposium, Munich, Germany, 22-27 July 2012.

120. Aguasca, A.; Acevo-Herrera, R.; Broquetas, A.; Mallorqui, J.J.; Fabregas, X. ARBRES: Light-weight CW/FM SAR sensors for small UAVs. Sensors 2013, 13, 3204-3216. [CrossRef]

(c)

(C) 2019 by the authors. Licensee MDPI, Basel, Switzerland. This article is an open access article distributed under the terms and conditions of the Creative Commons Attribution (CC BY) license (http://creativecommons.org/licenses/by/4.0/). 